\title{
A!
}

This is an electronic reprint of the original article.

This reprint may differ from the original in pagination and typographic detail.

Silander, Katariina; Torkki, Paulus; Lillrank, Paul; Peltokorpi, Antti; Brax, Saara A.; Kaila, Minna

\section{Modularizing specialized hospital services}

\section{Published in:}

International Journal of Operations and Production Management

DOI:

10.1108/IJOPM-06-2015-0365

Published: 01/01/2017

Document Version

Peer reviewed version

Please cite the original version:

Silander, K., Torkki, P., Lillrank, P., Peltokorpi, A., Brax, S. A., \& Kaila, M. (2017). Modularizing specialized hospital services: Constraining characteristics, enabling activities and outcomes. International Journal of Operations and Production Management, 37(6), 791-818. https://doi.org/10.1108/IJOPM-06-2015-0365

This material is protected by copyright and other intellectual property rights, and duplication or sale of all or part of any of the repository collections is not permitted, except that material may be duplicated by you for your research use or educational purposes in electronic or print form. You must obtain permission for any other use. Electronic or print copies may not be offered, whether for sale or otherwise to anyone who is not an authorised user. 


\title{
Modularizing specialized hospital services: constraining characteristics, enabling activities, and outcomes
}

\author{
Author Details: \\ Katariina Silander (corresponding author) \\ M.D., M.Sc. (Econ., B.A.) \\ Department of Industrial Engineering and Management, HEMA-Institute; Aalto University School of Science; Espoo \\ and University of Helsinki; Helsinki, Finland \\ katariina.silander@aalto.fi \\ Paulus Torkki \\ D.Sc. (Tech.) \\ Department of Industrial Engineering and Management, HEMA-Institute, Aalto University School of Science; Espoo, \\ Finland \\ Paul Lillrank \\ Ph.D., Professor of Quality and Service Management \\ Department of Industrial Engineering and Management, Aalto University School of Science; Espoo, Finland
}

\section{Antti Peltokorpi}

D.Sc. (Tech.), Assistant Professor

Department of Civil Engineering, Aalto University School of Engineering; Espoo, Finland

Saara A. Brax

D.Sc. (Tech.), Postdoctoral Researcher

Department of Industrial Engineering and Management; Aalto University School of Science; Espoo, Finland

\section{Minna Kaila}

M.D., Ph.D., Professor of Medical Management

Public Health Medicine; University of Helsinki and Helsinki University Hospital; Helsinki, Finland

\section{Acknowledgments}

This study was a part of an Energizing Urban Ecosystems research program carried out by RYM Ltd., - Strategic Centre for Science, Technology and Innovation for Built Environment. The research program was funded by Tekes and partner companies. In addition, the study received funding from Academy of Finland (grant no 274327). The funders had no part in planning or conducting the study or analyzing the findings. Finally, the authors express their gratitude for the constructive and insightful criticisms provided by the anonymous Reviewers. 


\begin{abstract}
Purpose: Modularity promises to relieve problems of complexity in service systems. However, limited evidence exists of its application in specialized hospital services. This study identifies enablers, constraints and outcomes of modularization in specialized hospital services.

Design: A qualitative comparative study of a hematology unit with modular service architecture and an oncology unit with integral service architecture in a university hospital is performed to analyze the service architectures, enablers and constraints of modularization, and outcomes.

Findings: A framework and five propositions combining the characteristics of specialized hospital services, enabling activities, and outcomes of modularization was developed. Modular service architecture was developed through limiting the number of treatment components, reorganizing production of standardized components into a separate service unit, and standardizing communication and scheduling in interfaces. Modularization increased service efficiency but diluted ownership of services, decreased customization, and diminished informal communication. This is explained by the specific characteristics of the services: fragmented service delivery, professional autonomy, hierarchy, information asymmetry, and requirement to treat all.

Research limitations/implications: Modularization can increase efficiency in specialized hospital services. However, specific characteristics of specialized care may challenge its application and limit its outcomes.
\end{abstract}

Practical implications: The study identifies enabling activities and constraints that hospital managers should take into account when developing modular service systems.

Originality/Value: This is the first empirical study exploring the enablers, constraints and outcomes of modularization in specialized hospital services. The study complements literature on service modularity with reference to specialized hospital services.

Keywords: Modularity, Service operations, Healthcare 


\section{Introduction}

Specialized healthcare services consist of secondary- and tertiary-level healthcare provided by medical professionals in hospital outpatient and inpatient units. The problems in this large and growing area are widespread and well-known: increased demand due to an aging population and developing diagnostics, cost inflation of treatment technologies, and concurrent over- and undertreatment. The healthcare sector faces major challenges to improve population health and patients' experiences and simultaneously reduce costs (Berwick et al., 2008). Patients demand more of a voice and care that is better tailored to their individual preferences. At the same time, the supply side in hospitals is fragmented into increasingly narrow specialties. Two megatrends collide: the demand for increasing service volumes, and the demand for customization.

Modularization and mass customization are seen as promising means to increase variety and customization in healthcare, while exploiting the advantages of mass production and standardization (Berwick, 1997; Bohmer, 2005; McLaughlin and Kaluzny, 2000). Modularization is expected to bring several benefits in services such as enhanced flexibility (Bask et al., 2010), increased variety (de Blok et al., 2013), and cost savings (Duray et al., 2000; Eissens-van der Laan et al., 2016) through reducing complexity in fragmented systems (Simon, 1962).

There is evidence of the benefits of modularization in healthcare (de Blok et al., 2013; Meyer et al., 2007; Soffers et al., 2014; Vähätalo and Kallio, 2015), but it remains scant in highly specialized hospital care. Can the implementation of modular service architecture deliver the promised outcomes? Previous research has identified design aspects of service modularization, such as customer involvement during the service process (Duray et al., 2000; Pekkarinen and Ulkuniemi, 2008; de Blok et al., 2010a, 2010b), managing heterogeneity of customer requests (Rahikka et al., 2011), decomposition of service offerings (Eissens-van der Laan et al., 2016), standardization of 
interfaces with design and planning rules (Baldwin and Clark, 1997; Chorpita et al., 2005; Pekkarinen and Ulkuniemi, 2008; van Liere et al., 2004), and the mixing and matching of components (Bask et al., 2011). These design aspects provide a good basis for understanding the application of modular service architecture in specialized hospital services, which in existing modularity research are characterized with high information asymmetry (Vähätalo and Kallio, 2015), professional autonomy (Van der Laan, 2015), heterogeneous demand, and continuous efforts to create new service and technological innovations (Vähätalo and Kallio, 2015). These characteristics are proposed to prevent or support modularity in healthcare. However, empirical investigations of modularization in specialized hospital services are scant, and the area is practically unexplored. There is a need for more knowledge on how modularity can be applied in daily service production activities: what is the role of the specific characteristics of specialized hospital services in the modularization process, what activities are required for the design of modular service architecture, and what are the outcomes of modularization?

This study explores modularization in specialized hospital services. To conduct a comparative case analysis, two units of a university hospital were studied: a hematology unit using a modular service architecture, and an oncology unit using an integral service architecture. Both hematology and oncology patients are severely ill, and their diseases are often fatal without adequate treatment. The specialties share other common characteristics, such as treatments with intravenous medications and evolving care toward outpatient ambulatory care. Based on the comparison of the units, the study identifies enablers and constraints related to modularization and its outcomes for service production. Furthermore, a framework is developed, and five propositions are formed for combining the identified characteristics of specialized hospital services, the enabling activities to design modular service architecture, and the outcomes of modularization. The study contributes to 
general service modularity literature by demonstrating how enabling activities in the design of modularization support change when specific service characteristics challenge modularization. In addition, the study demonstrates how the outcomes of modularization may be influenced by specific service characteristics in the context of specialized hospital care.

The paper is structured accordingly: first, it discusses modularity as a concept based on the literature and how service and healthcare characteristics affect modularization. Second, the empirical case context and methods for this study are described. Third, the service architectures of the case units are analyzed, and the enablers and constraints related to modularization of the hematology unit are identified, with discussion of the outcomes of modularization. Building on these, the study develops a framework that combines the identified characteristics of specialized hospital services, the enabling activities to design modular service architecture, and the outcomes of the modular system. The paper concludes by discussing the findings of the study in the context of earlier literature about service modularity and by providing practical suggestions to managers.

\section{Theoretical background}

\subsection{Main principles and aims of modularity}

In one of the most-used definitions, Baldwin and Clarke (1997) define modularity as constructing complex products or processes from independently designed smaller subsystems that function together as a whole. A core concept in modularity is decomposability: the division of a larger system into smaller parts (Simon, 1962; Voss and Hsuan, 2009). When a system is divided into smaller parts — modules — the interdependencies between the modules are minimized compared to the interdependencies inside modules (Ethiraj and Levinthal, 2004; Simon, 1962). This enables the 
simplification of interfaces because interactions within modules are more frequent or complex than those between modules (Salvador, 2007). The standardized interfaces between modules enable reusability and sharing (Pekkarinen and Ulkuniemi, 2008; Sanchez and Mahoney, 1996; Voss and Hsuan, 2009), and the separation and recombination of modules make it possible to create different configurations without losing functionality (Schilling, 2000). The standardization of interfaces supports the ability to copy or repeat modules, which enables mass production (Duray et al., 2000) and reduces coordination costs (Eissens-van der Laan et al., 2016).

Thus, it can be said that modularity is a systems concept that describes the following architectural aspects: the degree to which a system can be separated into components, the level of coupling between these components and the recombination of the components (Schilling, 2000). A matrix approach to analyze the decomposability of tasks between subsystems has been developed by Simon (1962). Based on this idea, the degree of modularity may be conceptualized as a continuum that ranges from an integral structure to a modular structure (Campagnolo and Camuffo, 2009). However, as components are always coupled to some degree, and only few systems have completely inseparable components, nearly all systems show modularity to some extent (Schilling, 2000).

Modularization in services is a new research area (Bask et al., 2010), and while seen as an important concept, it has not been widely applied to designing and producing services (Baldwin and Clark, 1997; Voss and Hsuan, 2009). Service modularity has been seen as a possibility for simplifying service production by dividing complex systems into more manageable subsystems and modules; enhanced flexibility, increased variety, and cost savings, among other factors, are considered to be benefits of modularization in service contexts (Bask et al., 2010; Carlborg and Kindström, 2014; Pekkarinen and Ulkuniemi, 2008; van Liere et al., 2004). However, 
modularization comes with tradeoffs. Modularization requires higher efforts during the design and development phases of services (Baldwin and Clark, 1997). Similarly, the standardization associated with implementing modularity may reduce variety in services (Vähätalo and Kallio, 2015), and it is not always clear whether the benefits of modularization outweigh the costs (Chorpita et al., 2005).

\subsection{Enablers and constraints to design and use of modularity in services}

In this study, enablers are defined as conditions that influence their target favorably, and these can be prerequisites or necessary conditions (cf. Dul et al., 2010) but not necessarily fully responsible causes of the resulting condition of the target. Constraints are defined as conditions that prevent, hinder, or otherwise negatively influence their target but not necessarily fully prevent the expected and targeted condition. Service features such as immateriality, heterogeneity of demand, inseparability of service production and use, perishability, and customer participation in the cocreation of value (Grönroos, 1998; Lovelock and Gummesson, 2004; Parasuraman, 1998; Sampson and Froehle, 2006; Vargo and Lusch, 2004), may hinder modularity by challenging the clear definition of modules and the creation of well-defined interfaces. Due to their immaterial and process-based nature, service modules are "softer" than physical product modules, i.e., service modules are more flexible and can often be varied ad-hoc unless they are fully automated (Bask et al., 2010; Brax, 2013). Hence, the boundaries and interfaces of a service module are not always discernible, and visible design rules, described by Baldwin and Clark (1997), are required to specify the service architecture and define clear interfaces between modules. The "softness" of service modules additionally challenges the possibility of decoupling services into independent 
modules because the interdependencies between service modules are often pooled, sequential, or reciprocal in character (Thompson, 1967).

The concept of co-creation changes the perspective of customers from passive receivers of services to active participants in the creation of the service. Thus, customer involvement in modularized services is a relevant aspect (Duray et al., 2000; Pekkarinen and Ulkuniemi, 2008) that should be possible during the service process (de Blok et al., 2010a, 2010b). Supporting patient involvement in service co-creation is especially important in the context of healthcare, as the patient is the center of the core service process regarding treatment, arriving at appointments as scheduled, providing sensitive information about themselves, and following treatment instructions at home. Correspondingly, the identification of heterogeneous customer requests in service production is required (Rahikka et al., 2011) as customer needs and requests affect both the content of the modules and the mixing and matching of service modules.

As service production and use are both inseparable and perishable, and as customer needs are heterogeneous, service production requires flexibility, adaptability, and robustness (Brax, 2013). These conditions may constrain the standardization of service modules and interfaces. Nonetheless, earlier studies demonstrate that in service modularization, the standardization of interfaces with design and planning rules is possible (Baldwin and Clark, 1997; Chorpita et al., 2005; Pekkarinen and Ulkuniemi, 2008; van Liere et al., 2004).

The creation of a modular operating model includes the design of a modular service architecture. In service production, the modularization of processes enables developing customized services from a limited number of modules (Carlborg and Kindström, 2014). The modularization of services often requires the modularization of the organization (Baldwin and Clark, 1997) as the clear division of work tasks to designated teams permits improvement within the independent 
modules. To succeed, modularization requires focused integration of the output of these individual teams through interfaces (Baldwin and Clark, 1997).

\subsection{Characteristics of specialized hospital services: implications for design and use of modularity}

Healthcare is a heterogeneous industry that consists of distinct service fields, such as elderly care and hospital care, which react to managerial methods in different ways (Dranove, 1998; Lillrank et al., 2015). Healthcare modularity studies have been carried out in areas such as mental care (Bushe et al., 2008; Chorpita et al., 2005; Weisz et al., 2012; Soffers et al., 2014), elderly or home care (de Blok et al., 2014, 2013, 2010a, 2010b), and in health insurance companies (Dörbecker et al., 2013). Hospital contexts have also been studied (Bohmer, 2005; Kuntz and Vera, 2007; Meyer et al., 2007), but to a lesser extent than elderly care. Thus, how the characteristics of specialized hospital services influence the modularization process and its outcomes should be considered.

In general, specialized hospital service providers are required to treat all in need (Bohmer, 2005). Thus, providers cannot choose their patients in order to focus in service production on certain patient segments. This increases variation: both customized and standard services are required as patient needs differ between individuals and patient groups. This is especially evident in university hospitals where both secondary- and tertiary-level care is provided. Treated patients vary from those with standardized high-volume medical needs, such as patients for cataract surgery, to those with highly customized needs, for example, clinical-trial patients or patients with rare diseases. In addition, patients with complex conditions require services provided by various professionals, such as physicians from different specialties, nurses, physiotherapists, and nutritionists. Currently, 
different hospital healthcare services are often categorized under different medical specialties. In other words, services are divided into siloes according to specialty departments (Vuorenkoski, 2008; Porter and Lee, 2013), which produce the different specialized services that patients require within the corresponding specialty (e.g., inpatient care in wards, outpatient care in the outpatient unit of the department). Thus, healthcare services are often fragmented between different departments and service providers, hindering common goals, and similar services may be produced under different specialties or healthcare units without collaboration in service production (Yen et al., 2010). In addition, the requirement to simultaneously produce customized and standardized services performed by various professionals in specialized hospital care increases the complexity of service production and may challenge modularization.

The complexity and high variety of patient needs have traditionally been managed within the patient-physician relationship. Consequently, a tightly coupled, integral service architecture has developed within the different fragmented healthcare units or departments characterized by strong professionalism, autonomy (cf. Cruess et al., 2002), and hierarchical levels between physicians and other personnel. Individual specialists' discretion and experience play an important role in decision-making and delivery of customized services, both of which, in principle contradict modularity. Although some services are mass-produced, professionalism and autonomy are still strongly associated with the delivery of specialized hospital services, which leads to a conflicting co-existence of mass production and professionalism (McLaughlin and Kaluzny, 2000). The conflict is compounded by the characteristically steep information asymmetry between professionals and patients (Lanseng and Andreassen, 2007). This asymmetry constrains the cocreation of services, because patients may not distinguish between their medical wants and needs (Berry and Bendapudi, 2007; Lillrank et al., 2010). As explained earlier, the asymmetry can 
challenge patient involvement, an essential part of service modularity in healthcare (de Blok et al., 2010a).

Studies in healthcare contexts provide major contributions to service modularity research by, for example, developing a theory of interfaces in service modularity (de Blok et al., 2014), and by studying the use of personalization in modularity (de Blok et al., 2013). Interfaces have two-fold aims; variety or coherence (de Blok et al., 2014). In addition, interfaces should be distinguished on two levels: the component level and the service package level (de Blok et al., 2014). In modular service architecture, the coordinated co-operation of healthcare professionals is necessary to enhance continuity of care and the efficient use of the often-fragmented independent service subunits. Seamless coupling is required in order to connect different modules in a way that supports variety (Chorpita et al., 2005). Single care plans have been seen as a way to increase coherence in cases where patients require services from different healthcare professionals (Meyer et al., 2007). However, in specialized hospital services, coordination of professionals and packaging of service components according to care plans might be a challenge as the number of service components, such as individual treatments, is typically high, and responsibilities to develop and produce components have been divided between a multitude of autonomous professionals.

Standardized health services help reduce information asymmetry, and standardized interfaces enhance patient flow (Vähätalo and Kallio, 2015). Modularization and the use of modular service architecture can be used as a means to streamline information flow and care coordination, and to reduce avoidable costs (Meyer et al., 2007; Soffers et al., 2014). Conversely, research demonstrates that healthcare personnel may argue against specifying interfaces as this may contravene professional autonomy (Van der Laan, 2015). Evidence is discordant regarding the benefits of modularization in healthcare as studies show that modularization can be used both to 
increase customization in care (de Blok et al., 2013) and to restrain it (Vähätalo and Kallio, 2015). Standardization is a prerequisite of effective modularization, but can also challenge it by restraining customization, competition, and new service and technological innovations (Vähätalo and Kallio, 2015).

In conclusion, existing research on service modularity and characteristics of specialized hospital services provide several concepts that can be used to explain and describe the application of modularity in specialized hospital services. The three most relevant elements of modularized services include: (i) the decomposition of services into well-defined modules and decoupling, with minimal interdependencies between modules; (ii) the connection of modules to each other, with standardized interfaces; and (iii) the recombining of modules to customize services to fulfill customer needs. Similarly, specialized hospitals can be considered as platforms to provide a wide range of heterogeneous services produced by healthcare professionals. The current study explores on five characteristics of specialized hospital services that are potentially relevant when explaining the traditional integral service architecture and identifying modularization constraints and enablers: (i) the need to treat all in need resulting in no possibility of focusing only on high-volume diseases; (ii) a fragmented delivery system with several highly specialized groups; (iii) professional autonomy; (iv) hierarchical relationships between personnel groups; and (v) information asymmetry between patients and providers.

\section{Methods}

The exploratory, inductive case study method is selected because it allows for the gathering of a full range of evidence within the specialized hospital care context (Yin, 2003). Purposive samples 
are useful for case studies that aim to build theory, as theory development does not require statistically representative samples of the studied population (Eisenhardt and Graebner, 2007). The comparative case analysis method, using two contrasting or polar cases, is effective for discovering characteristics that are pertinent in specific conditions (Voss et al., 2002). This study compares two contrasting cases to identify differences between the service architecture of a traditional or unmodularized hospital unit and that of a modularized hospital unit, enablers and constraints related to the design and use of modularity, and the outcomes of modularization. The study plan was approved by the hospital's Coordinating Ethics Committee.

\subsection{Case selection}

The research project was triggered by the identification of an interesting case (cf. Eisenhardt 1989; Voss et al., 2002): a day-hospital providing specialized outpatient care to patients from different specialties within the larger university hospital. When the day-hospital was established in 2010, some, but not all, specialty care units relocated subsets of their care processes into the day-hospital, creating an organizational context in which some units operated with a redesigned service architecture and other units continued without any changes. This situation provides a rare opportunity to conduct comparative analysis within a single parent organization; i.e., to compare the pre-existing and the redesigned service architecture to provide specialty healthcare service. (The two service architectures are described in detail in Results Section 4.1.)

Thus, following purposive sampling logic (Barratt et al., 2011; Eisenhardt and Graebner, 2007; Patton, 2002) two specialty units were chosen after preliminary assessment: hematology and oncology. The hematology unit operates in the redesigned service constellation with the day- 
hospital (representing a positive case), whereas the oncology unit has remained unchanged (negative case). During case selection, the preliminary assessment of the units focused on two areas: ensuring that the operations and service architecture in these units is clearly different when examined using key principles of modular design, and that the treatment processes in these specialties are similar to the extent that they can be considered comparable. Thus, the cases are expected to produce different results based on their known differences (Voss et al., 2002).

The assessment indicated that the hematology unit expresses higher levels of modularity in terms of well-defined modules, decoupling with minimized interdependencies, and standardized interfaces between modules. The oncology unit has a more integral design in terms of higher coupling between the outpatient services of the unit and less standardized interfaces between different outpatient services compared to the modularized hematology unit. These findings were further verified in the in-depth case analysis. In addition, the medical care demands of oncology and hematology patients are similar, although the operating models of the units are different. Since the oncology unit operates in the way that hospital units have operated for years in the case hospital and, more broadly, in the studied geographical area, this pre-existing and established service architecture is called "traditional." Thus, in this study, traditional service architecture refers to the common way of dividing services according to specialty and of producing services within these specialties, creating a unit with a broad set of service tasks produced by a single organizational department. For example, in the case of oncology, patients receive both inpatient and outpatient care services in units that are under the oncology department and that share a common pool of personnel. Using the terminology of the modularity continuum concept, such service architectures can be considered as integral. As a result, the hematology unit was selected as the representative case for the increased modularity in the service design, and the oncology unit was chosen as the 
contrasting case, to represent the pre-existing, more integral service production system, in short, the traditional system.

The study analyzes enablers and constraints that may affect modularization and identifies outcomes of modularization on hematology service production. The analysis focuses on the outpatient care of patients, because the outpatient services including the day-hospital and outpatient clinic were redesigned with a modular service architecture whereas the day-hospital and outpatient clinic in oncology use a traditional service architecture.

A day-hospital, also known as an outpatient care unit, is where treatments such as intravenous medications and short procedures are carried out. Patients visit the unit from home as ambulatory care patients. The day-hospital differs from other service phases of patient episodes in hematology and oncology. Both hematology and oncology require complex and customizable care processes, and reciprocal interdependencies are the norm in university hospital care. Physicians are in charge of the entire care process for the patient. Yet, day-hospital care is a service that can be provided more independently than many other phases of the care process. The day-hospital treatments and procedures can be carried out in a factory-like environment with standardization and high volumes. The packaging of patient care in hospitals is complex, and patients often need various day-hospital services (treatments and procedures) according to the phases of their episode, which require the mixing and matching of day-hospital services to customize the episodes. Thus, day-hospital services can be decoupled from other service phases in the care process without affecting the possibility of treating severely ill patients requiring well-coordinated and customized care. 


\subsection{Data collection and analysis}

Data were collected from multiple sources including interviews, treatment and procedure instructions, scheduling frames, and unit field-visits of both specialties to enable triangulation of information (Eisenhardt, 1989; Voss et al., 2002; Yin, 2003). In spring 2015, 16 semi-structured interviews with open questions and verifying closed questions were conducted to get detailed, firsthand information of the modularized and traditional operating models (Table 1). The interviews were analyzed as the primary data source and documents such as treatment instructions and scheduling frames, and field visits were used to enhance understanding of the service delivery systems and to validate interview findings.

All interviewees were involved in either the planning or the actual provision of the services or both (Table 1). Personnel from different levels of the organizational hierarchy, groups and functional areas were interviewed to limit informant bias (Eisenhardt and Graebner, 2007). All participants gave written informed consent. Notes were taken during the interviews. The interviews lasted from 33 to 103 minutes (median 62 minutes) and were recorded and transcribed; the transcriptions were sent to interviewees to verify accuracy and correctness (Johnston et al., 1999). Because practitioners were interviewed, common language instead of specialized modularization terminology was used in the interviews. Nevertheless, the interviews covered design aspects of modularity such as interfaces, modules, and service design and architecture, as well as the achieved outcomes. 
Table 1: Interviewed personnel members from the hematology and oncology units

\begin{tabular}{|l|l|c|l|c|c|}
\hline & Operating model & $\begin{array}{l}\text { Physicians } \\
\text { Specialists and } \\
\text { consultants }\end{array}$ & $\begin{array}{l}\text { Nurses } \\
\text { Head and assistant } \\
\text { head nurses, staff } \\
\text { nurses }\end{array}$ & $\begin{array}{l}\text { Ward } \\
\text { Clerk }\end{array}$ & Total \\
\hline $\begin{array}{l}\text { Hematology } \\
\text { unit }\end{array}$ & $\begin{array}{l}\text { Modular service production } \\
\text { with a modular service } \\
\text { architecture }\end{array}$ & 4 & 3 & 1 & $\mathbf{8}$ \\
\hline Oncology unit & $\begin{array}{l}\text { Traditional integral service } \\
\text { architecture }\end{array}$ & 2 & 5 & 1 & $\mathbf{8}$ \\
\hline Total & & $\mathbf{6}$ & $\mathbf{8}$ & $\mathbf{2}$ & $\mathbf{1 6}$ \\
\hline
\end{tabular}

The treatment instructions and field-visits supported the transcribed interviews to identify differences and similarities in the design and delivery of services. During field visits, the focus was on facilities, service layouts, and understanding real-life service delivery, which helped to improve understanding of the construction of the organization and its facilities. In hematology, a scheduling system from the Electronic Patient Record system was demonstrated to clarify the scheduling process of the day-hospital. The findings of the cases were discussed within the research group to enhance a common understanding of the similarities and differences of the two cases.

The first phase of the qualitative analysis was a within-case analysis followed by the second phase, a cross-case analysis (Eisenhardt, 1989; Miles et al., 2014) of the two cases. In the within-case analysis, the interview data were analyzed and coded manually. In the first phase, the transcribed interviews of both hematology and oncology were read independently, and first-level observations were identified in both cases (Table 2). In addition, treatment instructions from both cases were studied to verify interview findings.

Translating direct observation into coded categories requires interpretation of the subject by the analyst doing the coding (Glaser and Strauss, 1967). In principle, the analyst makes decisions on which descriptions and phrases represent certain phenomena or on which terms are synonymous. 
For example, the following citation was coded into the first-level observation category, labeled "Standardization has streamlined and simplified service production of outpatient care" because the interviewee describes how the unit, formerly perceived as "restless," has become organized and systematic since the new service architecture:

The new modularized day-hospital has made the functioning of the system more organized, systematic, and calm... before, the outpatient care unit and outpatient clinic was a lot more restless. (Interview 10)

Altogether, six informants indicated observations representing this category, using phrases such as "clear process," "focus on core job," and direct access to service. That several informants reported consistent observations using versatile terminology, thereby validating each other's perceptions, indicates that the observation code is saturated.

The cross-case analysis was carried out to understand how the service architecture of hematology has changed in comparison to the traditional service architecture of oncology. In this phase, the first-level observations of hematology and oncology were compared, and the first-level observations that were found only in hematology were included in the further analysis as oncology was a negative case with no modularization (Table 2). This enabled a focus on findings that were present only in hematology and the elimination of the characteristics that may be inherent to this particular hospital, and correspondingly, to specialized hospital service production in general. The reasons for exclusion or inclusion of the first-level observations are documented in Table 2, where the included first-level observations are arranged under second-level concepts based on inductive analysis. Then, the second-level concepts were analyzed in relation to service architecture, enablers and constraints, and outcomes of modularization (in Sections 4.1, 4.2, and 4.3). Finally, 
a framework was developed to combine the characteristics of specialized hospital services, activities to enable the design of modular service architecture and outcomes of the system.

\section{Modularizing specialized hospital services-empirical findings}

\section{from the university hospital}

The interview findings advancing the theory were categorized into service architecture, enablers and constraints of modularization, and outcomes of modularization. Enablers refer to factors and conditions that influence the studied outcome favorably or even as prerequisites, and constraints refer to factors and conditions that prevent or hinder modularization. The choice of terminology is deliberate, because, in a case study with a limited number of cases, a single variable cannot be controlled to the extent that distinguishing prerequisites from enablers would be possible. The term "outcome," in this article, thus refers to the outcomes associated with the redesign of the service architecture based on modularization principles. Table 2 demonstrates the categories of first-level observations from the data and how these were categorized into the second-level concepts, following the principles of inductive theory building (Glaser and Strauss, 1967; Eisenhardt, 1989). In addition, a set of first-level observations were found to be common to both service architectures and thus could not be considered as design aspects exclusive to modularity. These are reported as excluded first-level observations in Table 2. The enablers, constraints, outcomes, and excluded observation categories are numbered in Table 2, and the following Results section refers to these numbers 
Table 2: Identified enablers, constraints, and outcomes of modularization in the case unit. Second level-concepts are defined only for the included first-level observations.

\begin{tabular}{|c|c|c|c|}
\hline Second-level concepts & $\begin{array}{l}\text { First-level observations: } \\
\text { Hematology unit interviews }\end{array}$ & $\begin{array}{l}\text { First-level observations: } \\
\text { Oncology unit interviews }\end{array}$ & $\begin{array}{l}\text { Inclusion or exclusion: } \\
\text { Decision and criteria }\end{array}$ \\
\hline \multicolumn{4}{|c|}{ Enablers and constraints of modularization } \\
\hline $\begin{array}{l}\text { Resistance in design of } \\
\text { modules and work tasks } \\
\text { (Constraint 1) }\end{array}$ & $\begin{array}{l}\text { Resistance to create nurse-led day-hospital where } \\
\text { treatments and procedures are carried out } \\
\text { (Interview Numbers } 9 \text { and 14) }\end{array}$ & & $\begin{array}{l}\text { Included: Researchers did not } \\
\text { observe findings related to this theme } \\
\text { in oncology }\end{array}$ \\
\hline \multirow[t]{2}{*}{$\begin{array}{l}\text { Creation of design rules } \\
\text { for module design } \\
\text { (Enabler 1) }\end{array}$} & $\begin{array}{l}\text { Clear rules of what the day-hospital component } \\
\text { instructions should include }(3,5,6,9)\end{array}$ & $\begin{array}{l}\text { Some agreement regarding service delivery, } \\
\text { no documented instructions of the whole } \\
\text { treatment phase for all (Informants } 1,4,7,8 \text { ) }\end{array}$ & $\begin{array}{l}\text { Included: Researchers observed that } \\
\text { there were no rules about what the } \\
\text { care instructions in oncology should } \\
\text { include }\end{array}$ \\
\hline & $\begin{array}{l}\text { Written instructions for day-hospital components } \\
(3,6,9,10,14,15)\end{array}$ & & $\begin{array}{l}\text { Included: Researchers observed that } \\
\text { no well-documented and standardized } \\
\text { documents were evident in oncology }\end{array}$ \\
\hline \multirow[t]{2}{*}{$\begin{array}{l}\text { Clear separation of } \\
\text { ownership of modules } \\
\text { and design rules } \\
\text { (Enabler 2) }\end{array}$} & $\begin{array}{l}\text { Day-hospital developed design rules for } \\
\text { component instructions and an appointment } \\
\text { scheduling template }(3,9,6,14)\end{array}$ & $\begin{array}{l}\text { Scheduling of visits not standardized as } \\
\text { personnel members improvise how, and by } \\
\text { which personnel group, done. }(1,2,4,7,12)\end{array}$ & $\begin{array}{l}\text { Included: As observed, the } \\
\text { hematology unit had clear } \\
\text { instructions about who was in charge } \\
\text { of what, whereas, in oncology, the } \\
\text { responsible personnel member got } \\
\text { scheduling visits was not clearly } \\
\text { instructed }\end{array}$ \\
\hline & $\begin{array}{l}\text { Outpatient clinics responsible for developing day- } \\
\text { hospital components }(3,6,9,10,14)\end{array}$ & & $\begin{array}{l}\text { Included: Researchers observed no } \\
\text { such findings in oncology }\end{array}$ \\
\hline \multirow[t]{2}{*}{$\begin{array}{l}\text { Clear division of work } \\
\text { tasks } \\
\text { (Enabler 3) }\end{array}$} & $\begin{array}{l}\text { Clarified division of work tasks between nurses } \\
\text { and ward clerks }(3,5,6,14)\end{array}$ & $\begin{array}{l}\text { No standardized task division between } \\
\text { personnel groups }(1,2,7,8,12)\end{array}$ & $\begin{array}{l}\text { Included: Researchers observed that } \\
\text { task division was clear between } \\
\text { personnel groups in hematology. } \\
\text { Observation indicated that this was } \\
\text { not the case in oncology }\end{array}$ \\
\hline & $\begin{array}{l}\text { New division of work tasks between physicians } \\
\text { and nurses }(5,9)\end{array}$ & $\begin{array}{l}\text { Depending on individual personnel } \\
\text { members, the scheduling visits vary }(1,2,4 \text {, } \\
7,8,12)\end{array}$ & $\begin{array}{l}\text { Included: Researchers observed that } \\
\text { task division was clear between } \\
\text { personnel groups in hematology. } \\
\text { Observation indicated that this was } \\
\text { not the case in oncology }\end{array}$ \\
\hline
\end{tabular}




\begin{tabular}{|c|c|c|c|}
\hline & Task division between ward clerks $(3,5,14)$ & & $\begin{array}{l}\text { Included: Researchers observed task } \\
\text { division between ward clerks in } \\
\text { hematology. No such observation } \\
\text { was made in oncology }\end{array}$ \\
\hline \multirow[t]{3}{*}{$\begin{array}{l}\text { Creation of scheduling } \\
\text { rules } \\
(\text { Enabler } 4)\end{array}$} & $\begin{array}{l}\text { Scheduling template for day-hospital components } \\
(3,6,9,14)\end{array}$ & & $\begin{array}{l}\text { Included: Researchers observed that } \\
\text { hematology has a scheduling } \\
\text { template for different treatments with } \\
\text { different lengths. Observations } \\
\text { indicated that oncology does not have } \\
\text { such a clear template or instructions } \\
\text { for scheduling different treatments }\end{array}$ \\
\hline & $\begin{array}{l}\text { Instructions how to schedule patients to day- } \\
\text { hospital }(3,5,6,9,11,14)\end{array}$ & $\begin{array}{l}\text { Process of scheduling patients differs } \\
\text { between personnel members }(1,2,4,7,12)\end{array}$ & $\begin{array}{l}\text { Included: Observations indicate no } \\
\text { scheduling rules in oncology, } \\
\text { whereas these rules exist in } \\
\text { hematology }\end{array}$ \\
\hline & $\begin{array}{l}\text { Treatments have standardized lengths and slots in } \\
\text { the outpatient scheduling system }(3,5,6,9,11 \text {, } \\
14)\end{array}$ & $\begin{array}{l}\text { No certain time-slots for different treatments } \\
(1,2,4,7,8 \text {, }\end{array}$ & $\begin{array}{l}\text { Included: Observations indicate no } \\
\text { findings in oncology that relate to } \\
\text { standardized scheduling instructions }\end{array}$ \\
\hline \multirow{2}{*}{$\begin{array}{l}\text { Creation of criteria for } \\
\text { patient and component } \\
\text { selection } \\
\text { (Enabler 5) }\end{array}$} & $\begin{array}{l}\text { To be included in day-hospital treatments } \\
\text { procedures must be produced } 20 \text { times yearly ( } 3 \text {, } \\
9 \text { ) }\end{array}$ & & $\begin{array}{l}\text { Included: No observations in } \\
\text { oncology related to this issue }\end{array}$ \\
\hline & $\begin{array}{l}\text { Documented criteria are used to ensure right } \\
\text { patient selection to day-hospital }(3,5,9,14)\end{array}$ & & $\begin{array}{l}\text { Included: No observations in } \\
\text { oncology related to this issue }\end{array}$ \\
\hline \multirow{2}{*}{$\begin{array}{l}\text { Creation of } \\
\text { communication rules } \\
\text { and channels between } \\
\text { outpatient clinics and } \\
\text { day-hospital } \\
\text { (Enabler 6) }\end{array}$} & $\begin{array}{l}\text { Communication instructions created to minimize } \\
\text { non-value-adding communication between units } \\
(3,5,9,14)\end{array}$ & $\begin{array}{l}\text { Communication methods vary between } \\
\text { outpatient clinic visits and day-hospital care. } \\
(1,2,4,8)\end{array}$ & $\begin{array}{l}\text { Included: Communication } \\
\text { instructions only present in } \\
\text { hematology. Oncology has varying } \\
\text { ways of communication }\end{array}$ \\
\hline & $\begin{array}{l}\text { Organized communication channels between } \\
\text { outpatient clinics and day-hospital }(3,9,14)\end{array}$ & $\begin{array}{l}\text { Communication both informal and formal } \\
\text { between outpatient clinic visits and day- } \\
\text { hospital care, no strict communication rules. } \\
(1,2,4,8,)\end{array}$ & $\begin{array}{l}\text { Included: Researchers observed } \\
\text { organized communication channels } \\
\text { only in hematology. There were no } \\
\text { standardized communication rules or } \\
\text { channels observed in oncology }\end{array}$ \\
\hline $\begin{array}{l}\text { Too wide a range of } \\
\text { different instructions for } \\
\text { packaging } \\
\text { (Constraint } 2 \text { ) }\end{array}$ & $\begin{array}{l}\text { Too complicated tasks for ward clerks, as } \\
\text { different specialties have different needs (14) }\end{array}$ & & $\begin{array}{l}\text { Included: No observations related to } \\
\text { these findings in oncology }\end{array}$ \\
\hline $\begin{array}{l}\text { Lack of patient } \\
\text { involvement in design of } \\
\text { modules and components }\end{array}$ & $\begin{array}{l}\text { No patient involvement in the design of the day- } \\
\text { hospital treatment and procedure components. ( } 3 \text {, } \\
5,9,10,11)\end{array}$ & & $\begin{array}{l}\text { Included: As service delivery and } \\
\text { architecture was not redesigned in } \\
\text { oncology, no findings related to }\end{array}$ \\
\hline
\end{tabular}




\begin{tabular}{|c|c|c|c|}
\hline $\begin{array}{l}\text { (Neither enabler nor } \\
\text { constraint) }\end{array}$ & & & $\begin{array}{l}\text { patient involvement in module design } \\
\text { were observed in oncology }\end{array}$ \\
\hline \multicolumn{4}{|c|}{ Outcomes of modularization } \\
\hline \multirow[t]{2}{*}{$\begin{array}{l}\text { All nurses carry out all } \\
\text { components (Outcome 1) }\end{array}$} & $\begin{array}{l}\text { All nurses in the day-hospital carry out all } \\
\text { components }(3,9)\end{array}$ & $\begin{array}{l}\text { Nurses are not able to carry out all } \\
\text { treatments }(4,7)\end{array}$ & $\begin{array}{l}\text { Included: Different observations in } \\
\text { oncology and hematology. }\end{array}$ \\
\hline & $\begin{array}{l}\text { No "matching" of nurses and patient (no named } \\
\text { nurses) }(3,5)\end{array}$ & $\begin{array}{l}\text { "Matching" profiles of patients and nurses in } \\
\text { day-hospital care }(1,4,7)\end{array}$ & $\begin{array}{l}\text { Included: Different observations, } \\
\text { with no personal matching in } \\
\text { hematology }\end{array}$ \\
\hline \multirow[t]{2}{*}{$\begin{array}{l}\text { Streamlined service } \\
\text { production } \\
\text { (Outcome 2) }\end{array}$} & $\begin{array}{l}\text { Standardization has streamlined and simplified } \\
\text { service production of outpatient care }(3,5,6,9 \text {, } \\
10,15)\end{array}$ & & $\begin{array}{l}\text { Included: No observations of } \\
\text { standardization, streamlining, or } \\
\text { simplification of outpatient service } \\
\text { production in oncology }\end{array}$ \\
\hline & $\begin{array}{l}\text { Ability to provide over } 80 \text { standardized treatment } \\
\text { and procedures to patients in over } 20 \text { specialties } \\
(3,9)\end{array}$ & $\begin{array}{l}\text { Day-hospital sub-units carry out treatments } \\
\text { of certain disease groups. }(4,7,8)\end{array}$ & $\begin{array}{l}\text { Included: Researchers observed that, } \\
\text { in hematology, the day-hospital } \\
\text { carries out a large set of services to } \\
\text { different patients groups from } \\
\text { different specialties, whereas the } \\
\text { oncology day-hospital treatments are } \\
\text { carried out in certain subunits of the } \\
\text { day-hospital }\end{array}$ \\
\hline $\begin{array}{l}\text { Streamlined official } \\
\text { communication } \\
\text { (Outcome 3) }\end{array}$ & Clear communication path $(3,5,9,14)$ & & $\begin{array}{l}\text { Included: No observations related to } \\
\text { clear communication paths in } \\
\text { oncology }\end{array}$ \\
\hline \multirow{2}{*}{$\begin{array}{l}\text { Standardization carried } \\
\text { out inside modules, less } \\
\text { variety and } \\
\text { customization of service } \\
\text { components (Outcome 4) }\end{array}$} & $\begin{array}{l}\text { Trial patients difficult to treat in day-hospital as } \\
\text { volumes are small and day-hospital processes are } \\
\text { standardized }(11,15)\end{array}$ & $\begin{array}{l}\text { Trial patients treated in the day-hospital by } \\
\text { day-hospital nurses }(12,13,16)\end{array}$ & $\begin{array}{l}\text { Included: Different observations } \\
\text { between oncology and hematology }\end{array}$ \\
\hline & $\begin{array}{l}\text { There is a challenge to combine customization of } \\
\text { trial patients and standardized treatments in day- } \\
\text { hospital }(11,15)\end{array}$ & $\begin{array}{l}\text { Day-hospital nurses customize treatments to } \\
\text { fulfill trial patient needs }(12,13,16)\end{array}$ & $\begin{array}{l}\text { Included: Different observations } \\
\text { between oncology and hematology }\end{array}$ \\
\hline \multirow[t]{2}{*}{$\begin{array}{l}\text { Loss of unofficial } \\
\text { communication and } \\
\text { relationships (Outcome } \\
\text { 5) }\end{array}$} & $\begin{array}{l}\text { Personnel members do not meet and communicate } \\
\text { unofficially as previously }(9,14)\end{array}$ & $\begin{array}{l}\text { Informal communication routes common. } \\
\text { Common meetings for everyone in all units } \\
\text { of specialty, staff members meet each other } \\
(1,7,12)\end{array}$ & $\begin{array}{l}\text { Included: Different observations } \\
\text { between oncology and hematology }\end{array}$ \\
\hline & $\begin{array}{l}\text { Outpatient clinic and day-hospital personnel } \\
\text { belong to different organizations in hospital }(3,5 \text {, } \\
9,14)\end{array}$ & Personnel belong to same unit $(7,8)$ & $\begin{array}{l}\text { Included: Different observations } \\
\text { between oncology and hematology }\end{array}$ \\
\hline
\end{tabular}




\begin{tabular}{|c|c|c|c|}
\hline \multirow{2}{*}{$\begin{array}{l}\text { Loss of ownership of } \\
\text { service production and } \\
\text { challenge to develop } \\
\text { modules further } \\
\text { (Outcome 6) }\end{array}$} & $\begin{array}{l}\text { Challenges to communicate responsibility of day- } \\
\text { hospital treatments to outpatient clinics }(3,9)\end{array}$ & & $\begin{array}{l}\text { Included: No observations related to } \\
\text { this issue in oncology }\end{array}$ \\
\hline & $\begin{array}{l}\text { Demotivation of personnel to continue developing } \\
\text { components in day-hospital }(6,9)\end{array}$ & & $\begin{array}{l}\text { Included: No observations related to } \\
\text { this issue in oncology }\end{array}$ \\
\hline \multirow{2}{*}{$\begin{array}{l}\text { Less flexibility in } \\
\text { communication with } \\
\text { patients (Outcome 7) }\end{array}$} & $\begin{array}{l}\text { Communication goes through outpatient clinics } \\
\text { making it less flexible }(9,14)\end{array}$ & $\begin{array}{l}\text { Patients contact named day-hospital nurse } \\
\text { directly to receive instructions. }(2,4,7)\end{array}$ & $\begin{array}{l}\text { Included: Different observations } \\
\text { between oncology and hematology }\end{array}$ \\
\hline & $\begin{array}{l}\text { Patients cannot contact nurses in day-hospital } \\
\text { directly. }(3,9)\end{array}$ & $\begin{array}{l}\text { Named-nurse system in day-hospital and } \\
\text { patient may contact nurse directly. }(2,4,7)\end{array}$ & $\begin{array}{l}\text { Included: Different observations } \\
\text { between oncology and hematology }\end{array}$ \\
\hline \multicolumn{4}{|c|}{ Excluded first-level observations } \\
\hline $\begin{array}{l}\text { Formal communication } \\
\text { (Excluded Observation 1) }\end{array}$ & $\begin{array}{l}\text { Formal communication through the electronic } \\
\text { patient record system from physicians to nurses } \\
\text { and ward clerks. }(5,6,9,14)\end{array}$ & $\begin{array}{l}\text { Formal communication through the } \\
\text { electronic patient record system from } \\
\text { physicians to nurses and ward clerks }(1,2,4 \text {, } \\
7,8,12,13,16)\end{array}$ & $\begin{array}{l}\text { Excluded: Similar observations in } \\
\text { both units, as both hematology and } \\
\text { oncology personnel use the ERP in } \\
\text { the same way to communicate }\end{array}$ \\
\hline $\begin{array}{l}\text { Care planning } \\
\text { (Excluded Observation 2) }\end{array}$ & $\begin{array}{l}\text { No single care plan is in use, the need is identified } \\
\text { and is under development. (5) }\end{array}$ & $\begin{array}{l}\text { No single care plans, daily nurse care plans } \\
\text { under development, }(1,4,7)\end{array}$ & $\begin{array}{l}\text { Excluded: No single care plan } \\
\text { summarizing all the care that patient } \\
\text { receives in either of the units. Thus, } \\
\text { observations are similar }\end{array}$ \\
\hline $\begin{array}{l}\text { Referral handling } \\
\text { (Excluded Observation 3) }\end{array}$ & Clear division of referral handling. $(6,15)$ & Clear division of referral handling. $(7,8)$ & $\begin{array}{l}\text { Excluded: Similar observations } \\
\text { related to referral handling in } \\
\text { oncology and hematology }\end{array}$ \\
\hline $\begin{array}{l}\text { Referral assessment } \\
\text { (Excluded Observation 4) }\end{array}$ & Clear process how referrals are assessed $(5,6)$ & $\begin{array}{l}\text { Process in how to go through referrals }(2,4 \text {, } \\
7,8)\end{array}$ & $\begin{array}{l}\text { Excluded: Similar processes of } \\
\text { referral processing observed in both } \\
\text { oncology and hematology }\end{array}$ \\
\hline $\begin{array}{l}\text { Support service } \\
\text { packaging } \\
\text { (Excluded Observation 5) }\end{array}$ & $\begin{array}{l}\text { Patients involved in customizing support services } \\
\text { packaging. }(1,3,5,15)\end{array}$ & $\begin{array}{l}\text { Patients involved in customizing support } \\
\text { services packaging. }(1,8,12)\end{array}$ & $\begin{array}{l}\text { Excluded: Similar observations } \\
\text { related to customizing support } \\
\text { services in oncology and hematology }\end{array}$ \\
\hline $\begin{array}{l}\text { Patient role in } \\
\text { production } \\
\text { (Excluded Observation 6) }\end{array}$ & $\begin{array}{l}\text { Passive role of patient in production of day- } \\
\text { hospital treatments and procedures }(5,9,10,11)\end{array}$ & $\begin{array}{l}\text { Passive role of patient in production of day- } \\
\text { hospital treatments and procedures }(2,12)\end{array}$ & $\begin{array}{l}\text { Excluded: Similar observations in } \\
\text { both oncology and hematology. No } \\
\text { difference in patient involvement in } \\
\text { service production between oncology } \\
\text { and hematology }\end{array}$ \\
\hline $\begin{array}{l}\text { Coupling of visits } \\
\text { (Excluded Observation 7) }\end{array}$ & $\begin{array}{l}\text { No one-stop tactic; treatments and physician visits } \\
\text { generally on different days }(3,5,9)\end{array}$ & $\begin{array}{l}\text { No one-stop tactic; treatments and physician } \\
\text { appointments generally on different days ( } 1 \text {, } \\
\text { 7) }\end{array}$ & $\begin{array}{l}\text { Excluded: Similar observations in } \\
\text { both oncology and hematology }\end{array}$ \\
\hline
\end{tabular}




\subsection{Descriptions of the service architectures of the compared units}

The interviews, field visits and treatment instructions were used to describe how modular service architecture has been applied to hospital care in hematology (Figure 1). The modularized dayhospital opened in November 2010. Before the re-design, the production of hematology services was based on integral architecture (see Figure 1), which was similar to the current architecture of the oncology unit 


\section{Oncology}

Integral (traditional) service architecture

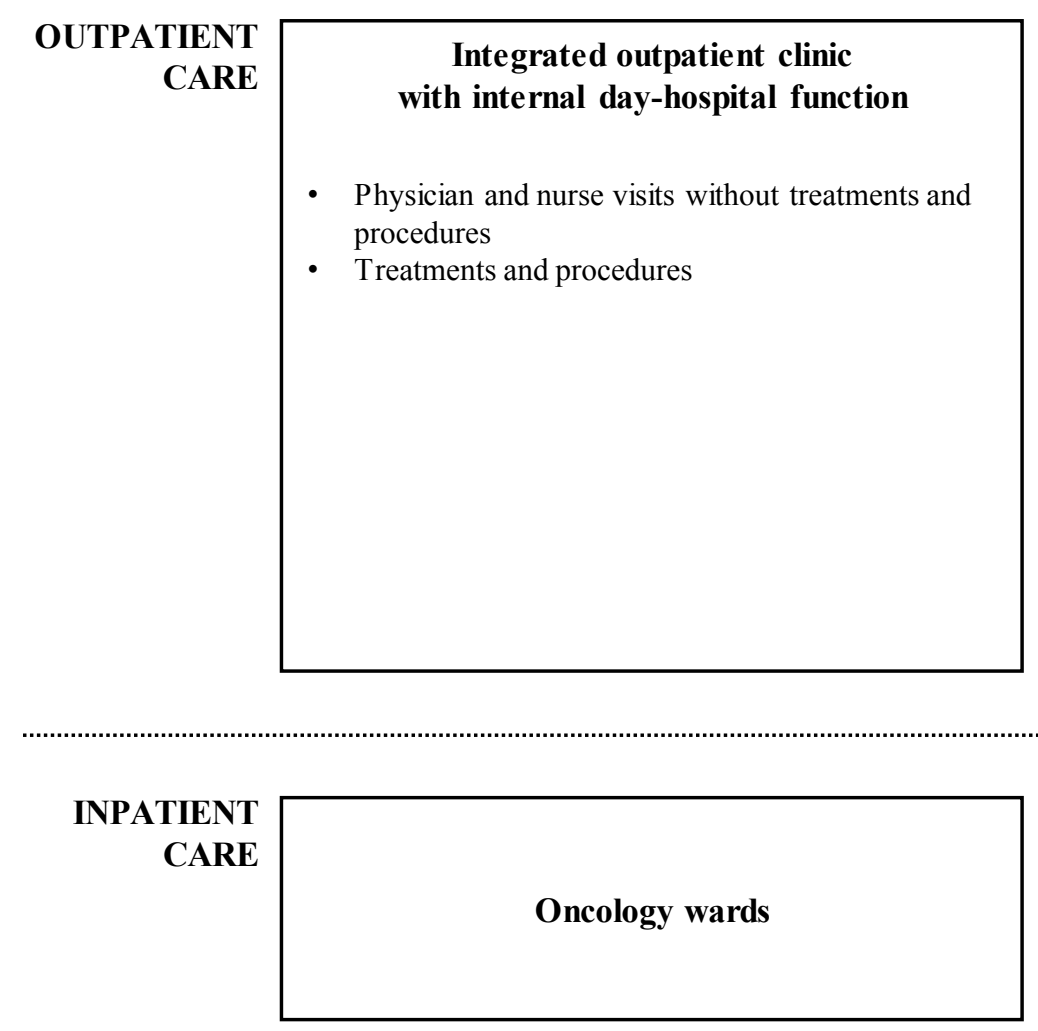

\section{Hematology}

Modularized (re-designed) service architecture

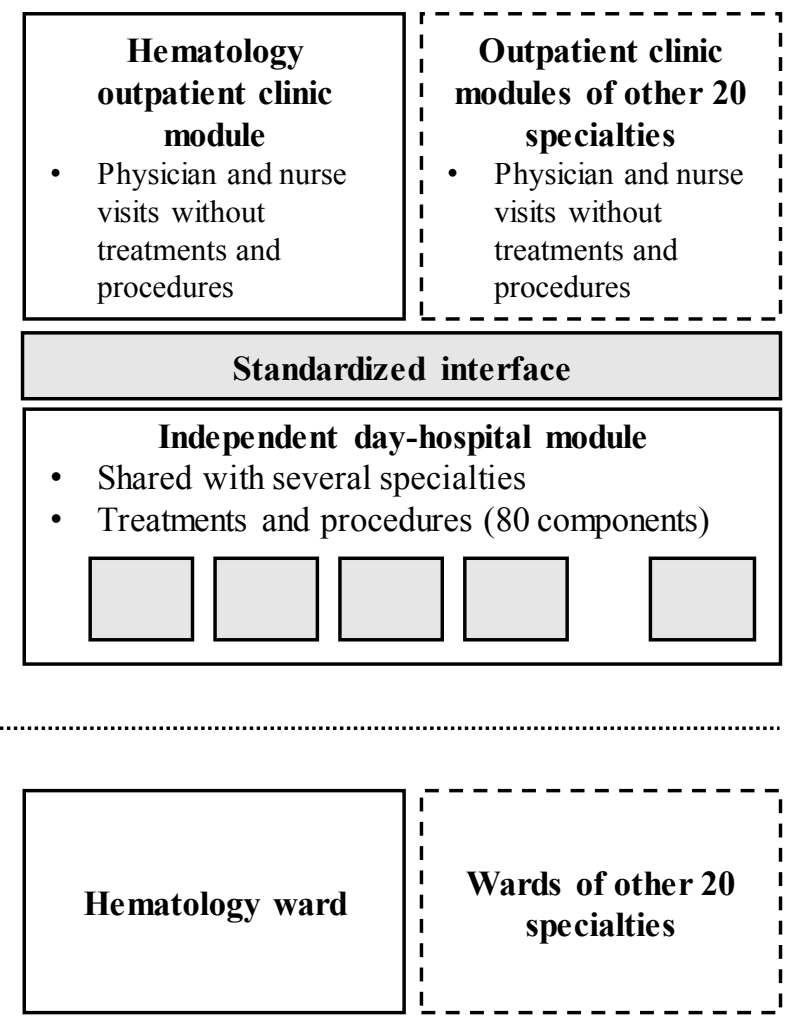


Figure 1: Service architecture of the hematology unit (modularized) and the oncology unit (integral). Prior to modularization, hematology had a similar architecture to oncology's current architecture.

\section{Traditional service architecture (oncology)}

Currently, the oncology unit has a service architecture that, as explained earlier (cf. Section 3.1), can be briefly labeled as traditional. In traditional service architecture, inpatient care is provided in wards, and outpatient ambulatory care is provided in the outpatient unit (see Figure 1). The service architecture inside wards and the outpatient unit is integral; physicians and nurses work closely together and they customize the content of patient visits according to patients' emerging needs. The outpatient unit delivers two service types: i) outpatient follow-up visits without treatments or procedures in the outpatient clinic; and ii) treatments and procedures in the internal day-hospital function. All personnel are under the same organization, and task division between members is not fully standardized and documented.

Another area that demonstrates integral service architecture and lack of standardization is the interface of the outpatient clinic and the internal day-hospital function. There is no documented scheduling system as all nurses manage their own patient lists in the internal day-hospital. Generally, patients arrive in two phases, in the morning or at noon. Nurses take care of several patients at the same time. Although treatment lengths vary, the reserved time-slots are generally the same for all treatments. Personnel communication between the internal day-hospital and outpatient clinic is not explicitly designed and planned. This indicates a less standardized interface 
and patient flow from outpatient clinic visits to internal day-hospital treatments, compared to the hematology unit operating with the modular service architecture.

The oncology internal day-hospital treats only oncology patients and carries out approximately 20,000 treatment sessions annually. The outpatient clinic hosts 25,000 outpatient visits annually. In the internal day-hospital, patients are assigned a named nurse, who carries out the patient's treatment scheme.

\section{Modularized service architecture (hematology)}

Currently, the hematology unit has a modular service architecture (Figure 1) and services are produced in three units; (i) the outpatient clinic hosting outpatient visits without treatments or procedures, (ii) the independent day-hospital carrying out outpatient treatments and procedures, and (iii) the hematology ward, in which inpatient care is carried out. The day-hospital is an independent organizational unit and does not belong to the hematology unit, although it produces day-hospital services for hematology patients. It is nurse-led and delivers 80 different, complex treatments and procedures to over 20 medical specialties, hematology being one of them. The dayhospital delivers approximately 16,000 treatment or procedure visits annually, of which, approximately half are hematology patient visits, which makes this patient group their largest service user. The day-hospital functions as an outsourced activity because the different medical specialties order necessary services from the day-hospital to fulfill the needs of their patients. 
The independent day-hospital is considered to be one module and the treatments and procedures as components of this module. Both the boundaries of the day-hospital services and the interfaces between the day-hospital module and outpatient clinics are clearly defined. All components, treatments or procedures in the independent day-hospital are standardized. A major difference to the traditional, more integral service architecture is that there are 21 nurses that treat all patients and nearly all standardized treatments and procedures can be carried out by every nurse. Because of this, patients have no named nurses and can have a different nurse every time they receive treatment in the independent day-hospital.

The separate outpatient specialty clinics, such as the hematology outpatient clinic, are responsible for the planning and development of the procedures and treatments (the components) of the dayhospital module. The independent day-hospital has created scheduling rules and instructions on how to book day-hospital services for patients. The different length of day-hospital services has been taken into account in the scheduling system and patients arrive throughout the day to receive care. The modularized day-hospital uses the same Electronic Patient Record (EPR) system as the oncology unit with traditional service architecture. The need for a more flexible EPR system to support modularity has been identified in the modularized day-hospital, but because the whole hospital uses the same system, there has been no change in the EPR system. The day-hospital has manually created scheduling lists in the EPR system to enable efficient scheduling.

As the independent day-hospital only provides standardized components (treatments and procedures), the heterogeneity of demand has been tackled through patient selection and inclusion criteria for treatments and procedures. Only treatment and procedures that are carried out for at least 20 patients annually can be included in the day-hospital. The procedures and treatments that 
require customization, or are produced less than 20 times annually, are carried out mostly in ward units.

\subsection{Enablers and constraints in the process of modularization}

Based on the interviews, two constraints were identified: There was skepticism towards the design of modules and work tasks, and the instructions for packaging services were too extensive. Altogether, six enablers influencing the process of modularization of the hematology unit were identified: design rules were developed for module design and scheduling; tasks were clearly divided; patient criteria were developed; communication rules and channels were standardized, and ownership of modules and design rules was defined (Table 2).

In the beginning, the idea of creating a modularized unit led by nurses was challenged (Constraint 1), which demonstrates how strong hierarchies impede new service architecture and subsequent reorganization. According to the interviewed experts, this constraint was overcome by strengthening the feeling of autonomous professionalism between physicians. The interviewees described how the constraints influenced the re-organization of services and how these challenges were overcome.

In the beginning physicians were reluctant to "give" their patients to a nurse-led day-hospital... They also doubted if treatments and procedures could be carried out as outpatient care. Physicians were given the responsibility to choose and decide the right patient groups to be treated in the dayhospital as outpatients. This patient selection has worked extremely well as only about 1\% of the day-hospital patients have had to stay in the hospital overnight. This in spite of the demanding 
procedures carried out in the day-hospital that elsewhere would be carried out as inpatient care.

(Interview 9)

During the modularization process, the outpatient clinic created documented instructions on how to carry out the day-hospital components. To facilitate this documentation process, the management of the independent day-hospital developed design rules of how to document the dayhospital component instructions (Enabler 1). According to the interviews, this ensured that all instructions of the day-hospital components (treatments and procedures) were documented in the same way and would include all relevant information. To facilitate modularization, the ownership of module design and execution was separated (Enabler 2). First, the management of the independent day-hospital took responsibility for developing design rules to create instructions for the day-hospital components. Second, the personnel of outpatient clinics, mostly physicians, followed the rules and took responsibility for creating instructions for the day-hospital components. Third, the treatment and procedure components of the independent day-hospital were then carried out by day-hospital personnel. This division of responsibilities supported the creation of a modular service architecture.

Another identified enabler was clear division of work tasks (Enabler 3). During the modularization process, responsibilities and work tasks between personnel groups were clarified, rearranged and documented. Moreover, the management of the independent day-hospital created documented scheduling rules (Enabler 4) to guide the scheduling of the day-hospital components. This supported efficient service production as the day-hospital works as a service factory (Schmenner, 2004) inside the hospital, with designated lengths for different treatment and procedure components. This was, for example, seen in the way how an interviewee described the independent day-hospital: 
We have rules on how to book the correct length of stay in treatment seats, so-called "hairdresser

chairs. "Some longer procedures are more difficult to predict, and there are certain "beds"

allocated for these treatments. (Interview 3)

Patient-selection criteria (Enabler 5) were developed to identify patient segments that could be treated in the new day-hospital. The independent day-hospital co-operates with over 20 different specialties and the communication rules between the day-hospital and outpatient clinics (Enabler 6) were created to streamline communication. In the beginning of use of the modularized service architecture, a constraint related to the packaging of services (Constraint 2) was identified. The independent day-hospital co-operated with many specialties, which had different needs, challenging the packaging of services carried out by ward clerks. This challenge was overcome by assigning tasks to specific ward clerks to ease the packaging of different services.

Although prior literature emphasizes customer involvement in service component specification and packaging (Duray et al., 2000; Pekkarinen and Ulkuniemi, 2008; de Blok et al., 2010a, 2010b), the interviews demonstrated that patient involvement was nonexistent in the design or packaging of the day-hospital service components. Thus, patient involvement in design is considered neither an enabler nor a constraint (cf. Table 2). Professionals designed the entire service architecture, the content of the modules and components, and the packaging of services.

\subsection{Outcomes of modularization}

The analysis revealed both positive and negative outcomes of modularization in the hematology unit (Table 2). Positive outcomes include streamlined service production and communication, as well as increased flexibility of resources, as nurses were able to carry out all components. 
However, after the redesign, communication with patients became less flexible, informal communication between personnel decreased, and there was diminished perceived ownership of service production.

The interviews demonstrated that, after the standardization of the day-hospital components and the creation of documented day-hospital instructions, all nurses have been able to carry out the 80 standardized treatments and procedures in the day-hospital (Outcome 1). According to the interviewed experts, this has increased efficiency as service supply is easier to adjust to dayhospital service demand because patient volumes are larger.

The interviewees pointed out that the standardization of services inside the day-hospital modules has streamlined service production (Outcome 2) and personnel are more aware of their tasks than previously. This has led to cost reductions. Before modularization, the first dosage of an intravenous treatment was often administered in the ward as inpatient care and only the later dosages were administered in the day-hospital as outpatient care. After modularization, in most cases, the whole treatment scheme has been carried out in the day-hospital without needing to admit the patient to wards. Due to modularization, the hospital has been able to close a ward, resulting in significant savings. Treatments are approximately $30 \%$ cheaper in the day-hospital compared to wards.

At the same time, communication has been streamlined (Outcome 3) between the outpatient clinic and the day-hospital after clear communication instructions were documented. Although the components in the day-hospital have been standardized, at times, day-hospital personnel members have the need to communicate with outpatient personnel. The communication instructions have streamlined paths of communication between these two units and enabled the day-hospital to focus 
on the production of day-hospital services. The interviewees recognized how communication instructions streamlined communication paths:

\footnotetext{
Information delivery is more efficient with formal information lists because we have to check less whether tasks have been carried out or not, and there is less running around trying to find the physician. Documented instructions for ward clerks enhance communication between services. (Interview 14)
}

Although modularization has had positive effects on service production, it has also created new challenges. As the day-hospital module is internally standardized through the standardization of day-hospital components, less variety and customization of service components is possible (Outcome 4), and therefore, some treatments are produced elsewhere in the hospital. The above challenge was not evident in the integral traditionally operating oncology unit as its day-hospital nurses can customize day-hospital services to fulfil trial patient needs. In the modularized hematology unit, however, the challenge is clearly seen with clinical-trial patients who require both standardized day-hospital services and customized services that are not carried out in the independent day-hospital:

\footnotetext{
Because of the standardization of the treatments and procedures in the day-hospital, customized ones are carried out by clinical trial nurses and physicians. The day-hospital requires written exact instructions, and at least for now it has not been seen as worthwhile to create these instructions with clinical patients as volumes are small. (Interview 11)
}

The creation of modular service architecture was supported by modularizing the organizational structure (Baldwin and Clark, 1997), as outpatient care and personnel were divided into two units: the outpatient clinic and the independent day-hospital. As personnel have been reallocated and the interfaces between these two units standardized, there is less of informal communication between personnel from different modules (Outcome 5). As a consequence, fewer informal relationships 
are formed. This has led to decreased collaboration between personnel members from different modules and between different personnel groups (e.g. physicians and ward clerks).

The interviewees pointed out that the redesign of service delivery, i.e., modular service architecture, and the separation of outpatient care into two units has led to a loss of ownership of service production and has challenged further development of modules (Outcome 6), as dayhospital treatments are no longer carried out in the same unit as were treatment decisions are made by physicians. When interfaces and components in modules are standardized, professionals inevitably lose part of their professional autonomy. Although this is an evident outcome of modularization, it has challenged service production, as autonomy is seen as a fundamental characteristic of healthcare professionals, especially physicians. As the execution and development of outpatient treatments and procedures have been divided between the outpatient clinic (responsibility for development) and day-hospital (responsibility for execution) it has hindered the outpatient clinic's motivation to continue developing treatment and procedure components in the day-hospital. Physicians have not been eager to work in the day-hospital as their role there is to ensure fluent patient flow, which has not traditionally been seen as important as clinical work. Physicians have felt that they have to carry out non-physician tasks because clinical work has been traditionally seen as the core task of physicians' work.

A new negative outcome related to patient communication has evolved; although the day-hospital carries out treatments and procedures, the outpatient clinics are responsible for communicating with the patient. This has made communication with patients less flexible (Outcome 7) as patients do not have a named nurse to contact in the day-hospital when questions arise during their treatment phases. Similarly, in case of sudden changes in day-hospital services requiring patient 
notification, patients have to be contacted by the outpatient clinic to receive this information, although the changes have occurred during day-hospital care.

\subsection{A framework linking the characteristics of specialized hospital services and the design and outcomes of modularization}

A framework is developed that combines the characteristics of specialized hospital services, enabling activities in the design of modular service architecture and outcomes of the modularization (Figure 2). This framework is based on the mapped modular service architecture in the hematology unit, the identified constraints and enablers for designing a modular architecture, and the identified outcomes of the modularization.

First, six activities were identified, which were used to design the elements of the modular service architecture by combining the identified enables and the characteristics of the modular service architecture in the hematology unit. Subsequently, using informants' explanations, the six identified activities were connected to five outcomes synthesized from the second-level concepts (Table 2). When possible, the outcomes and the activities for designing the modular service architecture were further connected to the five identified specialized hospital service characteristics: professional autonomy, hierarchical relationships, fragmented delivery system, requirement to treat all in need, and information asymmetry. 


\section{Activities to design elements of}

Characteristics of specialized hospital services

\section{modular service architecture}

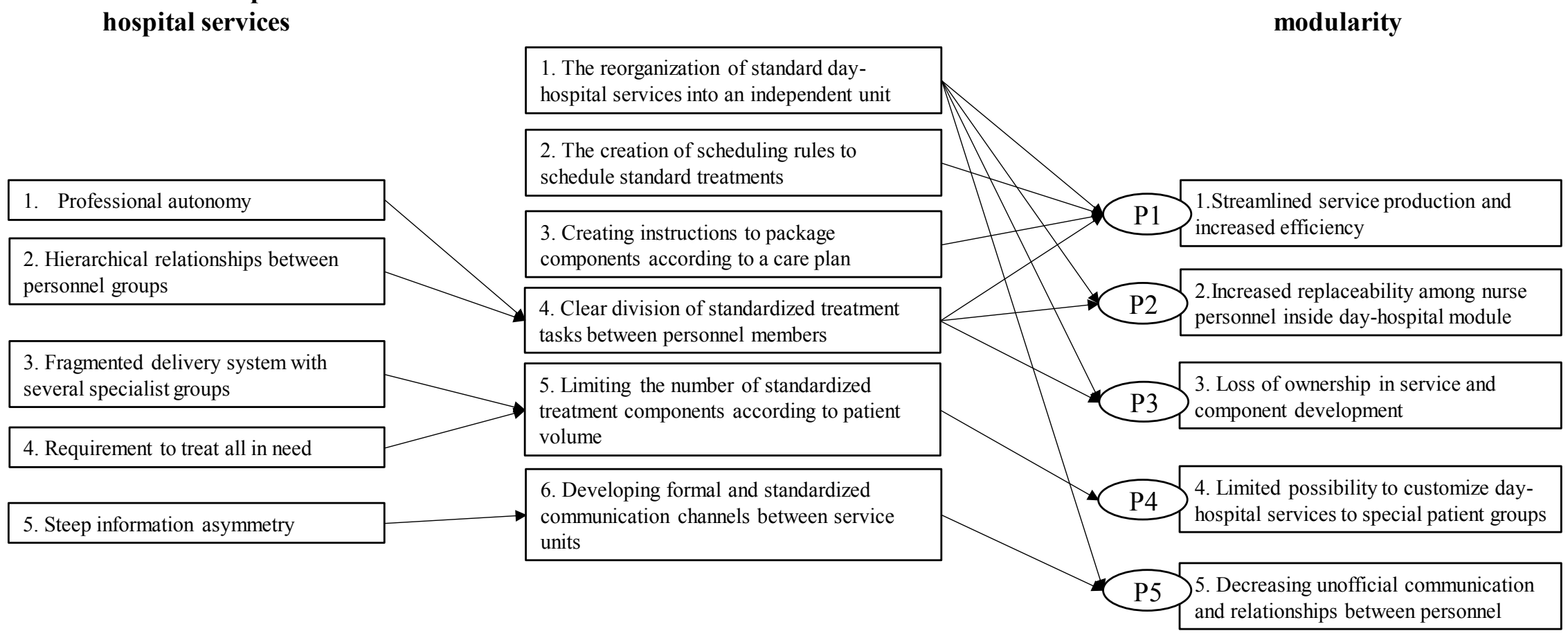

Figure 2: A framework combining the empirical findings related to the modularization of specialized hospital services in the case study hospital. 
The characteristics of specialized hospital services, together with the six design activities and the five outcomes, form five effect-chains, one for each outcome, which are expressed as five propositions.

Streamlined service production and increased efficiency

Proposition 1. The reorganization of standard service components into a separate unit with clear task division, scheduling rules, and instructions promotes streamlined service production and increased efficiency.

In the hematology unit, separating standardizable parts of the service into the day-hospital unit set natural limits for the duration and content of the service components. Treatments that were moved from the ward units to the day-hospital had to be modified according to the new outpatient environment. Systematic transfer of tasks from physicians to nurses increased learning, which again improved service efficiency. Standard rules to schedule treatments supported not only resource efficiency, but also flow of services from a patient point of view. Contrarily, in the oncology unit, standard scheduling rules did not exist, and scheduling practices differed between individual personnel members.

Modularization, however, streamlined services and thus a ward unit was closed due to an increased share of outpatient services produced in the new day-hospital. This finding supports earlier research that has reported the importance of process-oriented decomposing of service offerings 
(Eissens-van der Laan et al., 2016) and of standardization of services and processes (Pekkarinen and Ulkuniemi, 2008) to achieve efficiency gains.

Increased replaceability among personnel

Proposition 2. Clear division of tasks between professionals and the standardization of service components enable increased replaceability among personnel and more robust human resource management.

The modular service architecture enabled more flexible resource management. In hematology, nurses' tasks are no longer related to the physicians' or nurses' personal preferences in each situation, but are subject to clearer task division between the personnel groups. The clear task division simplified human resource management, and enabled rapid reallocation of nurses between scheduled tasks, without the need to cancel or delay scheduled treatments in the day-hospital unit. This finding indicates how modularity can be used to solve the complex work design problem in hierarchical service organizations (Sinha and Van de Ven, 2005).

While the first two propositions describe the possibilities that a modular service architecture can bring to specialized hospital services, the last three propositions illustrate the constraints and negative outcomes of modularization in the context.

Loss of ownership in service and component development

Proposition 3. Professional autonomy combined with hierarchical relationships constrains the standardization and task division between personnel groups. This, together with 
reorganizing services into independent units, challenges modular system improvement through diminished ownership of service development.

The division of treatments into the two units enabled standardization and streamlined hematology services, but also narrowed the earlier more autonomous role of physicians in service development. In an integral service architecture of the oncology unit, physicians have autonomy to modify and package treatments according to their own expertise and also to direct the nursing workforce to support that craft work. In the modularized service, the physician's role is to design treatment and procedure components of the day-hospital and to make decisions about necessary services. However, they have limited possibilities for tailoring components in the making and definition of new rules to package service components. At the unit level, this led to diminished ownership of the whole service system as design and execution of the treatment and procedure components were separated. As a result, further improvement of day-hospital components was challenged. The physicians' dual role — as healer and professional (Cruess et al., 2002)—was challenged as more autonomy was given to nurses, who have traditionally been lower in the hospital hierarchy.

\section{Limited possibility to customize services to special patient groups}

Proposition 4. Combined with the requirement to treat all in need, the fragmented delivery system involving several specialist groups constrains the standardization of all services. Standardization limits possibilities to provide services for special patient groups.

The requirement to limit service components to a manageable number, an element inherent in the modular service system of the hematology unit, contradicted two characteristics of specialized hospital services: i) fragmented division of the treatment of a patient between professionals, in 
which different specialty-centered units operate independently with limited communication or commonality of goals (Yen et al., 2010), and ii) the impossibility of focusing only on high-volume treatments. The day-hospital module provides service components for several medical specialties. As the case study hospital is a university hospital, specialties treat large numbers of patients with highly customizable needs; thus, not all patients and treatments fulfill the requirement for 20 patient cases per year. Consequently, all patients cannot be treated in the day-hospital, and those requiring customized treatments and procedures are often treated elsewhere in the hospital.

\section{Lack of unofficial communication and relationships between personnel}

Proposition 5. Formal and standardized communication channels between separated service units constrain informal communication and relationships between personnel, increasing information asymmetry between professionals.

The communication rules between the outpatient and day-hospital units were standardized in order to enable a smooth flow of patients from specialist outpatient units to standardized treatments and procedures in the new day-hospital module. Only formal communication channels, such as the referral system and the EPR, were used in the hematology unit whereas, in the oncology unit, staff members met each other informally more often. The official communication routes, and the 
separation of the outpatient clinic and day-hospital personnel, led to diminished unofficial meetings and information sharing in hematology. The separation of personnel members into different organizations created a feeling of "us" and "them" that further diminished unofficial communication. This was seen as a challenge as informal discussions and relationships between personnel members were considered important for managing information asymmetry between personnel groups. This finding emphasizes that, in addition to service modules, the interfaces between service modules are flexible (Bask et al., 2010; Brax, 2013) and may not benefit from an overly controlled approach. This case indicates that informal communication is needed to establish social relationships that can facilitate service production as “"organizational glue” between process modules and personnel groups.

\section{Discussion}

This study describes the process of modularizing the service architecture of a specialized hospital unit. The analysis identified six activities used to design the modular service architecture in the case study unit, the positive and the negative outcomes of the modularization, and explained how specific characteristics of specialized hospital services constrain modularization and its outcomes. By combining the above findings, the study developed a framework and formed five effect-chains expressed as five propositions to enhance understanding of the application of modularity in specialized hospital services.

The service design activities identified in the study are in line with earlier modularity literature, with the exception of patient involvement. The independent day-hospital module was decoupled from the rest of hematology service production, and interdependencies between modules were 
minimized through standardized interfaces and planning rules (Baldwin and Clark, 1997; Chorpita et al., 2005; Pekkarinen and Ulkuniemi, 2008; van Liere et al., 2004). Similarly, the mixing and matching of modules and the components of the independent day-hospital module were carried out to create different configurations of patient care, without losing functionality, a finding similar to earlier studies (Bask et al., 2011; Schilling, 2000). Although prior studies consider customer involvement an important aspect of modularization (Duray et al., 2000; Pekkarinen and Ulkuniemi, 2008; de Blok et al., 2010a, 2010b), patient involvement was not evident in the design of the independent day-hospital's services. The minor role of patient involvement in the design and packaging may be linked to the steep information asymmetry between healthcare professional and the patient, an essential characteristic of specialized hospital services. Thus, in the light of the current findings, patient involvement appears to be an enabler, not a critical prerequisite for service modularization.

The five specific characteristics of specialized hospital services-professional autonomy, hierarchy, fragmented delivery, requirement to care all needs, and information asymmetry-that affected the design and outcomes of modularization in the case unit, were similar to those presented in earlier research (Vähätalo and Kallio, 2015; Van der Laan, 2015). However, while earlier research has proposed that specific characteristics can either support or prevent modularization in healthcare, the findings of this research argue more specifically that the characteristics can be considered mostly as constraints, either by challenging the design of a modular service architecture or by limiting its outcomes. The findings demonstrate, how not only political governance (Vähätalo and Kallio, 2015), but also professional culture, causes inertia in transformation from traditional operating models toward modular service architecture. 
The identified outcomes of modularization were linked to specialized hospital services characteristics. Some of the outcomes were less favorable, because they clashed with the essential characteristics of specialized hospital services. For an example, the standardization of interfaces challenged professional autonomy (Cruess et al., 2002) by redistributing power relations. The identified clashes between the essential characteristics and the outcomes of modularization may play a role in explaining the limited applications of modularization to specialized hospital services.

The study emphasized the requirement to be able to customize specialized hospital services, a characteristic that was evident especially in relation to trial patients and patients requiring special treatments or procedures. The standardization of the day-hospital components were seen restrictive to service customization. These findings support earlier studies that have pointed out that healthcare professionals may see the specification of interfaces as contradictory to professional autonomy (Van der Laan, 2015) or restrictive to customization through standardization (Vähätalo and Kallio, 2015). The findings indicate that the optimal solution could be to consider specialized hospitals as multi-service platforms (Meyer et al., 2007), in which different units work as modules. The different levels of the standardization of module contents enable the fulfilling of different needs of patients and care production.

Modularization has both positive and negative effects on hospital service production. The findings suggested that modularization can streamline patient flow and communication between different service phases. The findings of this study demonstrated that modularization enhanced patient flow between the outpatient clinic and the independent day-hospital and were similar to findings of prior literature (Vähätalo and Kallio, 2015). According to observations, the enhanced patient flow was largely due to streamlined communication, an outcome that has also been discussed in the literature (Meyer et al., 2007; Soffers et al., 2014). The observations related to decreased treatment costs in 
the modularized unit also support the findings of previous studies (Duray et al., 2000; Eissens-van der Laan et al., 2016).

However, this study demonstrated that in addition to benefits, modularization challenges service production in specialized hospitals. The standardization of service components and strict patientselection criteria can decrease variety and flexibility in service production. Although in the case it did not limit customization of treatments and procedures on the whole-hospital level, it challenged the streamlining of patient care requiring outpatient services that were not produced in the modularized day-hospital. These findings are contradictory to earlier studies in elderly care context (de Blok et al., 2010a) in which modularization increases customization. The current study indicates, that in specialized hospital care, modularization can be used as a way to move from craftsmanship toward standardization in the product-process matrix (Hayes and Wheelwright, 1979a, 1979b), a direction opposite to that discovered by de Blok et al. (2010a) in the elderly care context. The finding underlines that outcomes of modularization are highly context-specific.

\section{Conclusions}

This is the first comprehensive study exploring the application of service modularity in specialized hospital services. Through a comparative case study of a modular and a traditional unit in a university hospital, a framework was developed that describes design activities, outcomes and constraining characteristics of modularization. The framework and the five propositions that depict the relation between service characteristics, design activities and outcomes may help healthcare managers to define their objectives and activities in modularization processes in order to gain sustainable value in service delivery. The study described an organization that has been able to 
apply modularity, demonstrating how conceptualizations of divided work tasks, modularized organizational processes, and focused integration through interfaces (Baldwin and Clark, 1997) enable the application of modularity. The study described how modular service architecture can be used in specialized hospital services by identifying a service phase that can be decoupled from the rest of the service production without disrupting overall service production. Moreover, the study identified that some outcomes of modularization facilitate service production whereas others create challenges.

\subsection{Theoretical contributions}

This research contributes to the literature on service modularity in three ways. First, the research contributes to service modularity literature by demonstrating how the enabling activities in the design phase support modularization of services when inherent characteristics of the service cause inertia in the modularization process. The study identified six activities that enabled the designing of modular service architecture in specialized hospital services. These activities explain how a traditional integral service architecture based on highly customized service components and nonstandardized interfaces between service providers is transformed into a modular service architecture. The findings are in line with earlier studies on design of service modularity, apart from the lesser role of patient involvement in this study. This can be explained by high information asymmetry between professionals and patients in specialized hospital services: the role of providers is highlighted both in design of service components and packaging of components according to patient needs. 
Second, the study identified positive and negative outcomes of modularization in specialized hospital services and connected those outcomes to the six identified design activities. Increased efficiency and improved human resource management are highlighted as positive outcomes whereas negative outcomes are related to loss of ownership, the limited possibility of carrying for all patients, and lack of informal communication and relationships. These findings are new in specialized hospital services and they complement the existing general research on service modularity as they depict how positive outcomes from modularization may be moderated due to changes in roles of professions, or due to the limited ability to focus on service offerings. Similar findings of limited outcomes could potentially also be found in other professional or public services.

Third, the study identified how the five specific characteristics of specialized hospital services constrain the design and outcomes of modularization. These characteristics, which are mostly related to the role and relationships of professions, are already identified in both service modularity and health service literature. However, this study elaborates on the existing literature by presenting concrete propositions of the detailed relationships between service characteristics, design activities and outcomes. The findings also explain the scant implementation of modularity in specialized hospital services: the strong professionalism of physicians, who are used to both producing and managing service contents and whole-service systems, is challenged when their tasks are limited to provision of standardized services. The findings increase knowledge on how field-based characteristics and roles of strong professions may limit the applicability of service modularization. 


\subsection{Practical contributions}

This study has several implications for managers aiming to modularize services in specialized hospital care. First, understanding and defining the scope of modularized services is crucial for success in the design phase and long-term outcomes. The case study indicated that modularization is applicable in treatment phases of the patient process where several sequential or periodical standardized service components need to be delivered. Instead, care of rare diseases and delivery of non-routine services are more challenging to standardize. Therefore, managers should carefully examine positive and negative consequences of modularization per service, design the service architecture accordingly for each service, and leave the most complex and rare services outside modularization.

Second, modularization changes the roles of professionals and personnel groups, and the changes have to be understood and managed in order to develop sustainable modularized service systems. In specialized hospital services, physicians traditionally have autonomy to modify the content of service events and customize service packages according to their expertise. Although a modular operating model would streamline processes and increase efficiency, in the long-term, managers should consider how to maintain physicians' inherent motivation to develop services. One possible solution, which was not fully applied in the case study, is to commit physicians to development through continuous assessment of care effectiveness in addition to efficiency and process outcomes.

The study provides practitioners with concrete examples of design activities that can be used when moving from a traditional craftsmanship type of operating model toward a modularized service system. The activities can be summarized into: limiting the number of treatment components; 
reorganizing production of service components into consistent service units; and standardizing communication and scheduling in interfaces. In other words, the validity of the traditional organization of specialized hospital services into specialties and their outpatient clinics can be questioned. Multi-specialty modules and units are needed to achieve critical volume to utilize standardized service components. In secondary- and tertiary-care hospitals, an optimal organizational structure would be a mix of highly modularized service sub-systems and units that provide more integral and customized services to meet the needs of rare diseases and project type patient episodes (Lillrank et al., 2010).

\subsection{Limitations and further research}

The comparative analysis enabled the research team to distinguish which enablers and constraints were related to the design and use of modularity, as the oncology unit acted as a negative case to which the findings of the hematology unit could be compared. Nonetheless, the identified enablers and constraints might not only be unique to modularization, but could relate to other forms of designing healthcare delivery. Accordingly, new empirical studies are needed to identify and further study the enablers and constraints related to the design and use of modularity. Similarly, the identified positive and negative outcomes related to modularization may be specific to the studied organization; thus, more research is needed to understand how modularization affects service production. The study is limited in terms of comparability, because both of the cases were within the same organization. An ideal sampling approach would have been to study many similar contrasting pairs of specialty departments with modular and non-modular configurations across different organizations within the same regulatory context. Finding enough such pairs to enable statistical analysis, however, is impossible. Here, the fact that the cases are from the same 
university hospital clarifies the case setup, because all other organizational conditions, except the modular service architecture, remain the same in both cases.

The study focused on the service provider perspective. As modularization affects both the service provider and the patients, how patients experience modularization should be explored in the future. In this study, the hematology patients had no named nurses, while oncology patients had them, but patients were not contacted individually for information.

Other empirical studies are needed to validate the developed propositions both in specialized hospital services and services in general. The study might not have identified all enablers or constraints related to modularization and outcomes as limited number of informants were interviewed, and misunderstandings are possible. In addition, many concepts found in this study have not been quantified, and evidence is based on interviewees' knowledge and experience, leaving some residual bias. Yet, the study questions were designed to be easily understandable and not to lead the interviewees. To increase reliability, a semi-structured interview guide was used (cf. Yin, 2003) in order to cover important design aspects of modularity, and to explore the challenges and outcomes related to modularization, and saturation patterns were identified (as demonstrated in Table 2). Overall, the study is the first to explore the enablers and constraints related to the application of modularity in specialized hospital services and to identify the positive and negative outcomes that modularization has on service production. Yet, to test the generalizability of the framework for creating a sustainable modular service system in specialized hospital services, further research is needed. 


\section{References}

Baldwin, C.Y. and Clark, K.B. (1997), "Managing in an age of modularity", Harvard Business Review, Vol 75 No. 5, pp. 84-93.

Barratt, M., Choi, T.Y. and Li, M. (2011), "Qualitative case studies in operations management: trends, research outcomes, and future research implications", Journal of Operations Management, Vol. 29 No. 5, pp. 329-342.

Bask, A., Lipponen, M., Rajahonka, M. and Tinnilä, M. (2010). “The concept of modularity: diffusion from manufacturing to service production", Journal of Manufacturing Technology Management, Vol. 21 No. 3, pp. 355-375.

Bask, A., Lipponen, M., Rajahonka, M. and Tinnilä, M. (2011), "Framework for modularity and customization: service perspective”, Journal of Business \& Industrial Marketing, Vol. 26 No. 5, pp. 306-319.

Berry, L.L. and Bendapudi, N. (2007), "Health care: A fertile field for service research", Journal of Service Research, Vol. 10 No. 2, pp. 111-122.

Berwick, D.M. (1997), “The total customer relationship in health care: broadening the bandwidth", Journal on Quality Improvement, Vol. 23 No. 5, pp. 245-50. 
Berwick, D.M., Nolan, T.W. and Whittington, J. (2008), "The triple aim: care, health, and cost", Health Affairs, Vol. 27 No. 3, pp. 759-769.

Bohmer, R.M. (2005), “Medicine's service challenge: blending custom and standard care”, Health Care Management Review, Vol. 30 No. 4, pp. 322-330.

Brax, S. A. (2013), The process based nature of services: Studies in management of industrial and business-to-business service. Aalto University School of Science, Espoo.

Bushe, C.J., McNamara, D., Haley, C., McCrossan, M. and Devitt, P. (2008), “Weight management in a cohort of Irish inpatients with serious mental illness (SMI) using a modular behavioural programme. A preliminary service evaluation”, BMC Psychiatry, Vol. 8 No. 76.

Campagnolo, D. and Camuffo, A. (2009), “The concept of modularity in management studies: A literature review", International Journal of Management Reviews, pp. 259-282.

Carlborg, P. and Kindström, D. (2014), "Service process modularization and modular strategies", Journal of Business \& Industrial Marketing, Vol. 29 No. 4, pp. 313-323.

Chorpita, B.F., Daleiden, E.L. and Weisz, J.R. (2005), "Modularity in the design and application of therapeutic interventions", Applied and Preventive Psychology, Vol. 11 No. 3, pp. 141-156. 
Cruess, S.R., Johnston, S., Cruess, R.L. (2002), "Professionalism for medicine: opportunities and obligations", Medical Journal of Australia, Vol. 177, pp. 208-211.

de Blok, C., Luijkx, K., Meijboom, B. and Schols, J. (2010a), "Modular care and service packages for independently living elderly", International Journal of Operations \& Production Management, Vol. 30 No. 1, pp. 75-97.

de Blok, C., Luijkx, K., Meijboom, B. and Schols, J. (2010b), “Improving long-term care provision: towards demand-based care by means of modularity", BMC Health Service Research, Vol. 10, pp. 278-290.

de Blok, C., Meijboom, B., Luijkx, K. and Schols, J. (2013), “The human dimension of modular care provision: opportunities for personalization and customization”, International Journal of Production Economics, Vol. 142 No. 1, pp. 16-26.

de Blok, C., Meijboom, B., Luijkx, K., Schols, J. and Schroeder, R. (2014), “Interfaces in service modularity: a typology developed in modular health care provision", Journal of Operations Management, Vol. 32 No. 4, pp. 175-189.

Dörbecker, R., Harms, T. and Böhmann, T. (2013), “Exploring prevalence, forms, and relationships of service modularity: a cross-sectional study of German private health insurance services", in: Service Excellence in Management: Proceedings of the 13th International 
Research Symposium on Service Excellence in Management (QUIS 13), CTF Center for Service Systems, Karlstad University, Sweden, pp. 193-201.

Dranove, D. (1998), "Economies of scale in non-revenue producing cost centers: implications for hospital mergers", Journal of Health Economics, Vol. 17, pp. 69-83.

Dul, J., Hak, T., Goertz, G., and Voss, C. (2010), “Necessary condition hypotheses in operations management", International Journal of Operations \& Production Management, Vol. 30 No. 11, pp. $1170-1190$.

Duray, R., Ward, P.T., Milligan, G.W. and Berry, W.L. (2000), “Approaches to mass customization: configurations and empirical validation", Journal of Operations Management, Vol. 18 No. 6, pp. 605-625.

Eisenhardt, K.M. (1989), "Building theories from case study research", Academy of Management Review, Vol. 14 No. 4, pp. 532-550.

Eisenhardt, K.M. and Graebner, M.E. (2007), “Theory building from cases: opportunities and challenges", Academy of Management Journal, Vol. 50 No. 1, pp. 25-32.

Eissens-van der Laan, M., Broekhuis M., van Offenbeek, M. and Ahaus, K. (2016), “Service decomposition: a conceptual analysis of modularizing services", International Journal of Operations \& Production Management, Vol. 36 No. 3, pp. 308-331. 
Ethiraj, S.K. and Levinthal, D. (2004), "Modularity and innovation in complex systems", Management Science, Vol. 50 No. 2, pp 159-173.

Glaser, B.G., and Strauss, A.L. (1967), The discovery of grounded theory, strategies for qualitative research, Aldine de Gruyter (Reprinted in 1999 ed.), Hawthorne, NY.

Grönroos, C. (1998), "Marketing services: the case of a missing product", The Journal of Business \& Industrial Marketing, Vol. 13 No. 4/5, pp. 322-338.

Hayes, R.H. and Wheelwright, S.G. (1979a), "The dynamics of process-product life cycles", Harvard Business Review, Vol. 57 No. 2, pp. 127-136.

Hayes, R.H. and Wheelwright, S.C. (1979b), "Link manufacturing process and product life cycles", Harvard Business Review, Vol. 57 No. 1, pp. 133-140.

Johnston, W.J., Leach, M.P. and Liu, A.H. (1999), "Theory testing using case studies in business-to-business research", Industrial Marketing Management, Vol. 28 No. 3, pp. 201-213.

Kuntz, L. and Vera, A. (2007), "Modular organization and hospital performance", Health Services Management Research, Vol. 20 No. 1, pp. 48-58. 
Lanseng, E.J. and Andreassen, T.W. (2007), “Electronic healthcare: a study of people's readiness and attitude toward performing self-diagnosis", International Journal of Service Industry Management, Vol. 18 No. 4, p. 394-417.

Lillrank, P., Chaudhuri, A. and Torkki, P. (2015), "Economies of scale in cardiac surgery", Journal of Hospital Administration, Vol. 4 No. 2, pp. 78-86.

Lillrank, P., Groop, P.J. and Malmström, T.J. (2010), “Demand and supply-based operating modes - a framework for analyzing health care service production", The Milbank Quarterly, Vol. 88 No. 4, pp. 595-615.

Lovelock, C. and Gummesson, E. (2004), "Whither services marketing? In search of a new paradigm and fresh perspectives", Journal of Service Research, Vol. 7 No. 1, pp. 20-41.

McLaughlin, C. and Kaluzny, A. (2000), "Building client centered systems of care: choosing a process direction for the next century", Health Care Management Review, Vol. 25 No. 1, pp. 7382.

Meyer, M.H., Jekowsky, E. and Crane, F.G. (2007), “Applying platform design to improve the integration of patient services across the continuum of care", Managing Service Quality: An International Journal, Vol. 17 No. 1, pp. 23-40. 
Miles, M.B., Huberman, A.M. and Saldaña, J. (2014), Qualitative Data Analysis: A Methods Sourcebook, SAGE Publications, Thousand Oaks, CA.

Parasuraman, A. (1998), "Customer service in business-to-business markets: an agenda for research”, Journal of Business \& Industrial Marketing, Vol. 13 No. 4/5, pp. 309-321.

Patton, M.Q. (2002), Qualitative Research and Evaluation Methods, Sage Publications, Thousand Oaks, California.

Pekkarinen, S. and Ulkuniemi, P. (2008), "Modularity in developing business services by platform approach", The International Journal of Logistic Management, Vol. 19 No. 1, pp. 84103.

Porter, M. and H. Lee, H. (2013), “The strategy that will fix health care”, Harvard Business Review, Vol. 91 No. 10, pp. 50-70.

Rahikka, E., Ulkuniemi, P. and Pekkarinen, S. (2011), "Developing the value perception of the business customer through service modularity", Journal of Business \& Industrial Marketing, Vol. 26 No. 5, pp. 357-367.

Salvador, F. (2007), “Toward a product system modularity construct: literature review and reconceptualization", IEEE Transactions on Engineering Management, Vol. 54 No. 2, pp. 219240. 
Sampson, S.E. and Froehle, C.M. (2006), "Foundations and implications of a proposed unified services theory", Productions and Operations Management, Vol. 15, No. 2 pp. 329-343.

Sanchez, R. and Mahoney, J.T. (1996), "Modularity, flexibility, and knowledge management in product and organization design", Strategic Management Journal, Vol. 17, Winter Special Issue, pp. $63-76$.

Schilling, M.A. (2000), “Toward a general modular systems theory and its application to interfirm product modularity", Academy of Management Review, Vol. 25 No. 2, pp. 312-334.

Schmenner, R.W. (2004), “Service businesses and productivity”, Decision Sciences, Vol. 35 No. 3, pp. 333-347.

Sinha, K., Van de Ven, A., (2005), "Designing work within and between organizations", Organization Science, Vol. 16 No. 4, pp. 389-408.

Simon, H.A. (1962), “The architecture of complexity”, Proceedings of the American Philosophical Society, Vol. 106 No. 6, pp. 467-482.

Soffers, R., Meijboom, B., van Zaanen, J. and van der Feltz-Cornelis, C. (2014), "Modular health services: a single case study approach to the applicability of modularity to residential mental healthcare", BMC Health Service Research, Vol. 14 No. 210, pp.1-10. 
Thompson, J.D. (1967). Organizations in Action: Social Science Bases of Administrative Theory, McGraw-Hill, New York.

Vähätalo, M. and Kallio, T.J. (2015), “Organising health services through modularity”, International Journal of Operations \& Production Management, Vol. 35 No. 6, pp. 925-945.

van der Laan M.R. (2015), The Feasibility of Modularity in Professional Service Design: Towards Low Cost Person-Centred Care. Rijksuniversiteit Groningen, Groningen.

van Liere, D.W., Hagdorn, L., Hoogeweegen, M.R. and Vervest, P.H. (2004), “Embedded coordination in a business network", Journal of Information Technology, Vol. 19 No 4. pp. 261269.

Vargo, S.L. and Lusch, R.F. (2004), "Evolving to a new dominant logic for marketing”, Journal of Marketing, Vol. 68, pp. 1-17.

Voss, C.A. and Hsuan, J. (2009), "Service Architecture and Modularity”, Decision Sciences, Vol. 40 No. 3, pp. 541-569.

Voss, C.A., Tsikriktsis, N., and Frohlich, M.T. (2002), “Case research in operations management", International Journal of Operations \& Production Management, Vol. 22 No. 2, pp. $195-219$. 
Vuorenkoski, L. (2008). Finland: Health system review, health systems in transition. Vol. 10, No 4. World Health Organisation., available at:

http://www.euro.who.int/_data/assets/pdf file/0007/80692/E91937.pdf (accessed 13.2.2017)

Weisz, J.R., Chorpita, B.F., Palinkas, L.A., Schoenwald, S.K., Miranda, J., Bearman, S.K., Daleiden, E.L., Ugueto, A.M., Ho, A., Martin, J., Gray, J., Alleyne, A., Langer, D.A., SouthamGerow, M.A. and Gibbons, R.D., (2012), “Testing standard and modular designs for psychotherapy treating depression, anxiety, and conduct problems in youth: a randomized effectiveness trial", Archives of General Psychiatry, Vol. 69, No. 3, pp. 274-282.

Yen, L., Gillespie, J., Jeon, Y-H., Kljakovic, M., Brien, J., Pearce-Brown, C., Jan, S., Lehnbohm, E., Usherwood, T. (2010), "Health professionals, patients and chronic illness policy: a qualitative study”. Health Expect. Vol. 14, pp. 10-20.

Yin, R.K. (2003) Case Study Research: Design and Methods, SAGE Publications, Thousand Oaks, CA. 